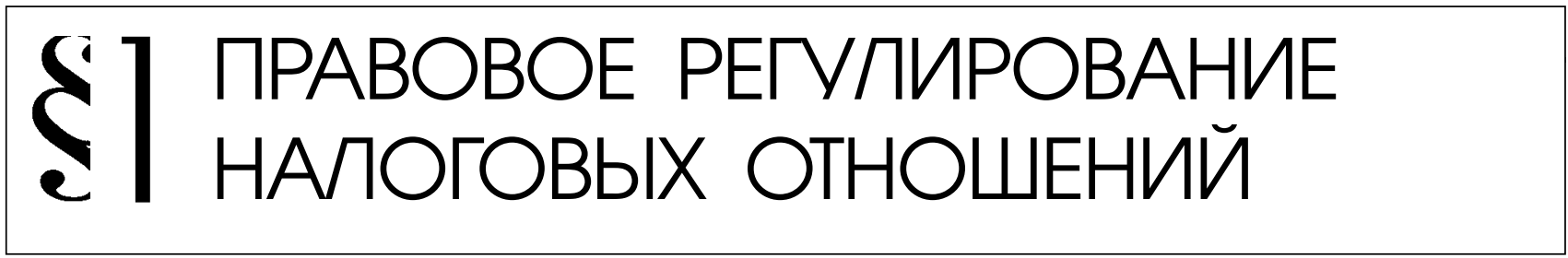

Сизова А.М.

\title{
НАЛОГОВЫЕ ПОСЛЕДСТВИЯ РЕОРГАНИЗАЦИИ И ЛИКВИДАЦИИ УЧАСТНИКОВ КОНСОЛИДИРОВАННОЙ ГРУППЫ НАЛОГОПЛАТЕЛЬЩИКОВ
}

\begin{abstract}
Аннотация: Введение системы консолидированного налогообложения было необходимым шагом на пути развития российской налоговой системы. Однако в силу своей новизны она представляет собой новый вызов как для налоговых органов, так и для налогоплательщиков. Являясь по сути особым налоговым режимом для холдингов, система консолидированного налогообложения должна учитывать их специфику, в частности распространенные в холдингах процессы структурирования в виде реорганизации и ликвидации организаций. В статье рассмотрены налоговые последствия данных процессов для участников консолидированных групп налогоплательщиков, в частности, проблемные вопросы повторных выездных налоговых проверок. Автором детально проанализирована нормативная правовая база, касающаяся вопросов реорганизации и ликвидации КГН. Особое внимание уделено актуальным формулировкам Налогового кодекса РФ и разъяснениям Минфина и ФНС России. По итогам проведенного анализа автором предложено внести изменения в положения НК РФ, касающиеся оснований проведения выездных проверок в связи с реорганизацией или ликвидацией организаций. Соответствующие изменения внесли бы определенность в налоговое законодательство и устранили бы риск возможных споров налоговых органов с налогоплательщиками, создавшими КГН.

Ключевые слова: Консолидированная группа налогоплательщиков, Холдинг, Реорганизация, Ликвидация, Участник КГН, Прекращение действия КГН, Налоговые органы, Налоговые последствия, Повторная выездная проверка, Налог на прибыль.
\end{abstract}

\section{Правовой статус и условия создания КГН}

Российские крупнейшие холдинги получили возможность создавать консолидированные группы налогоплательщиков (КГН) с 1 января 2012 года. Таким образом, институт консолидированного налогоплательщика применяется в российской налоговой системе уже два года. И если преимущества для государства от создания КГН крупнейшими налогоплательщиками на данном этапе находятся под вопросом, то выгодность данного варианта для органи- заций под сомнение не ставится. Основными причинами заинтересованности компаний в создании КГН являются, во-первых, непризнание сделок между участниками одной и той же КГН контролируемыми, и, во-вторых, возможность суммировать прибыли и убытки внутри КГН, тем самым снижая налоговую нагрузку на группу.

Согласно российскому налоговому законодательству консолидированной группой налогоплательщиков признается добровольное объединение налогоплательщиков налога на прибыль организаций на основе договора о создании КГН в целях исчисле- 
ния и уплаты налога на прибыль организаций с учетом совокупного финансового результата хозяйственной деятельности указанных налогоплательщиков ${ }^{1}$. Важно отметить, что КГН представляет собой добровольное объединение отдельных самостоятельных хозяйствующих субъектов. Таким образом, КГН выступает специфическим субъектом налоговых отношений и имеет особый правовой статус: консолидированная группа не является юридическим лицом, а действует на основании договора о создании группы, который имеет смешанную, налогово-правовую, природу.

Введение института консолидации, как и любые другие значительные преобразования налоговой системы РФ, является начальной точкой трудоемкого процесса выстраивания взаимоотношений между налогоплательщиками и государственными органами. ${ }^{2}$ В связи с этим следует обратить внимание на ряд потенциальных трудностей, с которыми могут столкнуться компании, создавшие КГН, в процессе своей деятельности. Поскольку КГН является выгодным вариантом для вертикально интегрированных структур, холдингам, создавшим КГН, необходимо внимательно следить за ситуациями, которые могут привести к прекращению действия договора. В частности, это относится к реорганизации и ликвидации участников консолидированной группы.

Согласно Гражданскому кодексу РФ существует 5 форм реорганизации: слияние, присоединение, разделение, выделение, преобразование. Форма реорганизации в

\footnotetext{
Статья 25.1 Налогового кодекса Российской Федерации 2 Кондрашова Н.А. Проблемные вопросы организации учета при создании консолидированной группы налогоплательщиков // Международный бухгалтерский учет. 2012. - № 42 (240). - Режим доступа: http://library.fa.ru/ res_elibrary_rus.asp.
}

первую очередь влияет на порядок правопреемства, в том числе на правопреемство в части исполнения обязанности по уплате налогов и сборов. Данные гражданскоправовые и налоговые последствия ликвидации и реорганизации применимы и к участникам КГН, однако помимо этого для данных организаций есть ряд особенностей, на которые им необходимо обратить внимание как на этапе создания КГН, так и в процессе функционирования и прекращения действия группы.

Организации, создающие КГН, должны соответствовать ряду специальных условий, установленных статьей 25.2 НК РФ. Одним из таких условий является то, что ни одна из организаций - потенциальных участниц создаваемой КГН не должна находиться в процессе реорганизации или ликвидации ${ }^{3}$. Невыполнение данного условия хотя бы одним из участников создаваемой КГН может быть основанием для отказа налоговым органом в регистрации договора о создании КГН. Подтверждением того, что организация не находится в процессе реорганизации или ликвидации являются выписки из ЕГРЮЛ. Также соблюдение условий может быть проверено путем направления письменного запроса в территориальные налоговые органы по месту нахождения участников создаваемой КГН ${ }^{4}$.

\section{Налоговые последствия реорганизации и ликвидации участников КГН}

Несмотря на то что при создании КГН ни один из ее участников не должен находиться в процессе реорганизации или ликвидации,

\footnotetext{
Пп.1 п.3 ст.25.2 Налогового кодекса РФ

4 См.: Письма Минфина России от 21.12.2011 № 03-0310/120, от 16.12.2011 № 03-03-06/1/831, ФНС России от 29.12.2011 № AC-4-3/22569@.
} 
в процессе функционирования КГН реорганизация участников возможна, но с оговоркой, что реорганизация ответственного участника КГН возможна лишь в форме преобразования, в то время как реорганизация остальных участников возможна и в других формах 5 . Однако процессы реорганизации и ликвидации участников КГН должны находиться под пристальным контролем группы. Налоговым кодексом РФ предусмотрены случаи, когда в договор о создании КГН должны быть внесены изменения, которые включают в себя, в частности:

- ликвидацию участника КГН;

- реорганизацию участника КГН в форме слияния, присоединения, выделения или разделения (налоговые органы обращают внимание, что реорганизация участника КГН в форме преобразования не приводит к необходимости внесения изменений в договор о создании КГН ) ${ }^{6}$. Данные изменения подлежат обязательной регистрации в налоговых органах, в противном случае данный договор прекращает действовать (ст. 25.4 НК РФ). Кроме того, КГН прекращает действовать и в других случаях, например, при реорганизации (за исключением реорганизации в форме преобразования), ликвидации ответственного участника КГН (п. 1 ст. 25.6 НК РФ).

Проблемные вопросы реорганизации и ликвидации участников КГН были уже затронуты в законопроекте №137425-6, внесенном осенью 2012 г. в Государственную Думу. Законопроект был снят с рассмотрения в связи с отзывом субъектом права законодательной инициативы, однако отдельные его положения не остались без внимания.

\footnotetext{
5 Письмо ФНС России от 20 марта 2012 г. № ЕД-43/4638@

6 Письмо ФНС России от 12.09.2012 № АC-4-3/15221@
}

В частности, в пояснительной записке к законопроекту обращалось внимание на то, что в случае реорганизации участника КГН путем присоединения к нему организации, не являющейся участником КГН, либо в случае выделения из организации - участника КГН организации, не включаемой в состав участников КГН, фактически не происходит изменений положений договора о создании КГН. Вследствие этого законопроектом предлагалось исключить необходимость перерегистрации договора путем дополнения соответствующей статьи Налогового кодекса РФ нормой, предусматривающей, что внесение изменений в договор в вышеуказанных случаях не требуется. Подобная норма позволила бы снизить излишние административные и бюрократические барьеры.

Несмотря на то что подобные изменения в Налоговый кодекс РФ не были внесены, данный вопрос не остался без внимания. В октябре 2013 года Минфин России выпустил письмо с разъяснением, что в вышеуказанных случаях заключение соглашения участников КГН об изменении договора о создании КГН и его регистрация в налоговых органах не требуется, если при этом не происходит изменения условий договора о создании КГН. При этом Минфин отметил, что условия, указанные в ст. 25.2 НК РФ, должны выполняться в течение всего срока действия договора, если Кодексом не предусмотрено иное ${ }^{7}$. Данное письмо направлено для сведения и использования в работе Письмом ФНС России от 02.12.2013 № ГД-4-3/21502@, которое размещено на официальном сайте ФНС России в разделе «Разъяснения ФНС, обязательные для при-

\footnotetext{
7 Письмо Минфина России от 29 октября 2013 г. № 03-03-10/45877 (направлено Письмом ФНС России от 2 декабря 2013 г. № ГД-4-3/21502@)
} 
менения налоговыми органами». Как известно, на основании Решения ВАС РФ от 06.03.2007 № 15182/06 такие письма, устанавливающие правовые нормы (правила поведения), обязательные для неопределенного круга лиц, могут быть квалифицированы в качестве нормативного правового предписания.

Однако в своих разъяснениях Минфин и ФНС России обращают внимание, что при ликвидации и любой реорганизации ответственного участника, кроме преобразования, КГН прекращает свое действие на основании п.1 ст. 25.6 НК РФ. Вместе с тем, вышеуказанным законопроектом предлагалось установить, что прекращение деятельности КГН возникает при ликвидации ответственного участника или реорганизации в форме присоединения, влекущее прекращение деятельности ответственного участника, как присоединенного лица ${ }^{8}$. С точки зрения автора, данное уточнение является обоснованным и его также следовало бы закрепить путем внесения изменений в соответствующие нормы Налогового кодекса РФ или письменного разъяснения ФНС России, обязательного для применения налоговыми органами.

\section{Проблемные вопросы при проведении выездной проверки в связи с реорганизацией и ликвидацией участников КГН}

Учитывая, что институт консолидированного налогоплательщика введен относительно недавно, арбитражная практика по вопросам проведения выездных налого-

\footnotetext{
8 Проект Федерального закона № 137425-6 «О внесении изменений в части первую и вторую Налогового кодекса Российской Федерации в части консолидированной группы налогоплательщиков и налогового контроля в связи с совершением сделок между взаимозависимыми лицами»
}

вых проверок в КГН еще не сформировалась. Однако анализ положений соответствующих статей Налогового кодекса РФ позволяет выявить возможные проблемные вопросы, с которыми могут в будущем столкнуться налоговые органы и налогоплательщики при проведении проверок, осуществляемых в связи с реорганизацией или ликвидацией участников КГН.

Так, согласно п.11 ст. 89 НК РФ выездная налоговая проверка, осуществляемая в связи с реорганизацией или ликвидацией организации-налогоплательщика, может проводиться независимо от времени проведения и предмета предыдущей проверки. Правила, предусмотренные статьей 89 НК РФ, распространяются и на проведение выездных проверок КГН с учетом особенностей, установленных статьей 89.1 НК РФ. Возможность проведения повторной выездной проверки КГН данной статьей предусмотрена (п. 7 ст. 89.1 НК РФ), однако никаких специальных положений относительно проведения выездных проверок в связи с реорганизацией или ликвидацией участников КГН Налоговым кодексом РФ не установлено. В связи с этим по данному вопросу необходимо руководствоваться общими правилами, установленными статьей 89 НК РФ.

Исходя из формулировки пункта 11 статьи 89 НК РФ, возможность проведения повторной выездной проверки установлена только при реорганизации или ликвидации налогоплательщиков, являющихся организациями. Никаких уточнений, что налоговые органы имеют право провести повторную выездную проверку при прекращении деятельности КГН, не установлено. Учитывая, что ликвидация и реорганизация как гражданско-правовые термины применяются к организациям, а КГН, как было отмечено ранее, юриди- 
ческим лицом не является, то, по мнению автора, при прекращении действия КГН по такому основанию, как расторжение договора о создании КГН по соглашению сторон, оснований для проведения повторной налоговой проверки нет.

В то же время среди оснований прекращения действия КГН предусмотрено такое обстоятельство как ликвидация ответственного участника КГН. Соответственно в отношении него у налоговых органов по ст.89 НК РФ возникает право проведения повторной выездной налоговой проверки. Однако учитывая, что проверяться будет период, когда данная организация входила в состав КГН и налогом на прибыль облагался совокупный финансовый результат всех хозяйствующих субъектов группы, налоговым органам необходимо будет провести выездную налоговую проверку по налогу на прибыль организаций в отношении всех участников КГН. Таким образом, у остальных участников КГН возникает риск того, что в отношении них также будет проведена повторная выездная проверка, хотя непосредственных оснований для этого Налоговый кодекс РФ не содержит.

Еще более сложный вопрос возникает при ликвидации или реорганизации остальных участников КГН, не являющихся ответственными. Например, два участника КГН реорганизуются путем слияния, и правопреемник после реорганизации продолжает находиться в составе КГН. Возникает вопрос, имеются ли правовые основания у налоговых органов для проведения повторной выездной налоговой проверки всей консолидированной группы, если реорганизация касалась только отдельных ее участников. При этом, строго говоря, данные участники КГН не признаются налогоплательщиками по налогу на прибыль, так как согласно ст. 246 НК РФ платель- щиком налога на прибыль организаций по КГН признается только ее ответственный участник. Исходя из существующих формулировок Налогового кодекса РФ, оснований для проведения повторной проверки в отношении всех участников группы нет, однако принимая во внимание опять же тот факт, что реорганизуются организации, являющиеся частью консолидированной группы, существует обоснованная необходимость провести повторную выездную проверку по налогу на прибыль в отношении всей группы.

\section{Заключение}

Холдинг является эффективной формой организации предпринимательской деятельности, поскольку позволяет сочетать гибкость и мобильность небольших формально самостоятельных организаций с масштабом деятельности крупных корпораций ${ }^{9}$. Однако холдинг не является статичной структурой, он постоянно находится в динамике, изменяясь под действием различных факторов. Учитывая распространенную практику структурирования внутри крупных холдингов, представляется целесообразным внести соответствующие изменения в Налоговый кодекс РФ по отмеченным в статье вопросам с целью совершенствования механизма налогового администрирования КГН. В частности, по мнению автора, п.11 статьи 89 НК РФ необходимо дополнить следующим образом: «выездная налоговая проверка, осуществляемая в связи с реорганизацией или ликвидацией организации-налогоплательщика, а также в связи с прекращением

\footnotetext{
9 Архипцева Л.М., Архипцева О.Н., Миронченко Т.С.. «Особенности холдингов как консолидированных налогоплательщиков» // Налоговая политика и практика. 2008. - №5. - Режим доступа: СПС «Консультант Плюс».
} 
действия консолидированной группы налогоплательщиков, может проводиться независимо от времени проведения и предмета предыдущей проверки». Кроме того в статье 89.1 НК РФ необходимо предусмотреть особенности проведения повторных выездных проверок, осуществляемых в связи с реорганизацией и ликвидацией участников КГН. В частности, указать, что при реорганизации или ликвидации участника КГН, не являющегося ответственным, повторная выездная налоговая проверка по налогу на прибыль организаций может проводиться в отношении всех участников КГН.

Такие изменения внесли бы определенность в налоговое законодательство и устранили бы риск возможных споров c налогоплательщиками в отношении правовых оснований для проведения налоговыми органами повторной выездной проверки в связи с реорганизацией и ликвидацией участников КГН.

\section{Библиография:}

1. Гражданский кодекс Российской Федерации: Часть первая-четвертая: [Принят Гос. Думой 23 апреля 1994 года, с изменениями и дополнениями по состоянию на 5 мая 2014г. ] // Собрание законодательства РФ. - 05.12.1994, № 32, ст. 3301.

2. Налоговый кодекс Российской Федерации: Часть первая и вторая [Принят Гос. Думой 16 июля 1998 года, с изменениями и дополнениями по состоянию на 4 июня 2014 г. ] // СЗ РФ. 3 августа 1998 г. № 31 ст. 3824.

3. Решение Высшего Арбитражного Суда Российской Федерации от 06 марта 2007 № 15182/06 // Доступ из справ. - правовой системы «КонсультантПлюс»

4. Письмо Минфина России от 29 октября 2013 г. № 03-03-10/45877 (направлено Письмом ФНС России от 2 декабря 2013 г. № ГД-4-3/21502@) // Доступ из справ. - правовой системы «КонсультантПлюс»

5. Письмо Минфина России от 21 декабря 2011 № 03-03-10/120 // Доступ из справ. правовой системы «КонсультантПлюс»

6. Письмо Минфина от 16 декабря 2011 № 03-03-06/1/831 // Доступ из справ. - правовой системы «КонсультантПлюс»

7. Письмо ФНС России от 12 сентября 2012 № AC-4-3/15221@ // Доступ из справ. - правовой системы «КонсультантПлюс»

8. Письмо ФНС России от 20 марта 2012 г. № ЕД-4-3/4638@ // Доступ из справ. - правовой системы «КонсультантПлюс»

9. Письмо ФНС России от 29 декабря 2011 № AC-4-3/22569@ // Доступ из справ. - правовой системы «КонсультантПлюс»

10. Проект Федерального закона № 137425-6 «0 внесении изменений в части первую и вторую Налогового кодекса Российской Федерации в части консолидированной группы налогоплательщиков и налогового контроля в связи с совершением сделок между взаимозависимыми лицами» // Доступ с сайта Государственной Думы PФ. URL: http:// asozd2.duma.gov.ru/main.nsf/\%28SpravkaNew\%29?0penAgent\&RN=137425-6\&02

11. Архипцева Л.М., Архипцева О.Н., Миронченко Т.С.. «Особенности холдингов как консолидированных налогоплательщиков» // Налоговая политика и практика. - 2008. №5. - Режим доступа: СПС «Консультант Плюс». 
12. Кондрашова Н.А. Проблемные вопросы организации учета при создании консолидированной группы налогоплательщиков // Международный бухгалтерский учет. 2012. - № 42 (240). - Режим доступа: http://library.fa.ru/res_elibrary_rus.asp.

\section{References:}

1. Grazhdanskii kodeks Rossiiskoi Federatsii: Chast' pervaya-chetvertaya: [Prinyat Gos. Dumoi 23 aprelya 1994 goda, s izmeneniyami i dopolneniyami po sostoyaniyu na 5 maya 2014g. ] // Sobranie zakonodatel'stva RF. - 05.12.1994, № 32, st. 3301.

2. Nalogovyi kodeks Rossiiskoi Federatsii: Chast' pervaya i vtoraya [Prinyat Gos. Dumoi 16 iyulya 1998 goda, s izmeneniyami i dopolneniyami po sostoyaniyu na 4 iyunya 2014 g. ] // SZ RF. 3 avgusta 1998 g. № 31 st. 3824.

3. Reshenie Vysshego Arbitrazhnogo Suda Rossiiskoi Federatsii ot 06 marta 2007 № 15182/06 // Dostup iz sprav. - pravovoi sistemy «Konsul'tantPlyus»

4. Pis'mo Minfina Rossii ot 29 oktyabrya 2013 g. № 03-03-10/45877 (napravleno Pis'mom FNS Rossii ot 2 dekabrya 2013 g. № GD-4-3/21502@) // Dostup iz sprav. - pravovoi sistemy «Konsul'tantPlyus»

5. Pis'mo Minfina Rossii ot 21 dekabrya 2011 № 03-03-10/120 // Dostup iz sprav. - pravovoi sistemy «Konsul'tantPlyus»

6. Pis'mo Minfina ot 16 dekabrya 2011 № 03-03-06/1/831 // Dostup iz sprav. - pravovoi sistemy «Konsul'tantPlyus»

7. Pis'mo FNS Rossii ot 12 sentyabrya 2012 № AS-4-3/15221@ // Dostup iz sprav. - pravovoi sistemy «Konsul'tantPlyus»

8. Pis'mo FNS Rossii ot 20 marta 2012 g. № ED-4-3/4638@ // Dostup iz sprav. - pravovoi sistemy «Konsul'tantPlyus»

9. Pis'mo FNS Rossii ot 29 dekabrya 2011 № AS-4-3/22569@ // Dostup iz sprav. - pravovoi sistemy «Konsul'tantPlyus»

10. Proekt Federal'nogo zakona № $137425-6$ «0 vnesenii izmenenii v chasti pervuyu i vtoruyu Nalogovogo kodeksa Rossiiskoi Federatsii v chasti konsolidirovannoi gruppy nalogoplatel'shchikov i nalogovogo kontrolya $\mathrm{v}$ svyazi s soversheniem sdelok mezhdu vzaimozavisimymi litsami» // Dostup s saita Gosudarstvennoi Dumy RF. URL: http://asozd2. duma.gov.ru/main.nsf/\%28SpravkaNew\%29?0penAgent\&RN=137425-6\&02

11. Arkhiptseva L.M., Arkhiptseva O.N., Mironchenko T.S.. «Osobennosti kholdingov kak konsolidirovannykh nalogoplatel'shchikov» // Nalogovaya politika i praktika. - 2008. - №5. Rezhim dostupa: SPS «Konsul'tant Plyus».

12. Kondrashova N.A. Problemnye voprosy organizatsii ucheta pri sozdanii konsolidirovannoi gruppy nalogoplatel'shchikov // Mezhdunarodnyi bukhgalterskii uchet. - 2012. - № 42 (240). - Rezhim dostupa: http://library.fa.ru/res_elibrary_rus.asp. 